\title{
MOTIVAÇÃO NO TRABALHO DOS SERVIDORES TÉCNICOS ADMINISTRATIVOS EM EDUCAÇÃO
}

\section{MOTIVATION IN THE WORK OF ADMINISTRATIVE SERVERS IN EDUCATION}

\author{
André Vasconcelos Silva ${ }^{1}$ \\ Fernanda Costa Barros ${ }^{2}$
}

\begin{abstract}
Resumo
O mundo do trabalho tem mudado muito nos últimos anos, devido à globalização, ao desenvolvimento tecnológico e a mecanização das atividades, levando as organizações a buscarem alternativas para se tornarem mais competitivas. A busca por um melhor desempenho nas organizações está intimamente ligada ao comportamento dos trabalhadores. Dentre os fatores que influenciam o comportamento dos trabalhadores, destaca-se a motivação e a satisfação no trabalho. Nesse contexto, este estudo tem o intuito de mensurar a motivação dos servidores técnicos administrativos ativos das instituições federais de ensino superior (IFES) do Estado de Goiás, tomando como referência a Teoria de Expectância de Vroom. A amostra da pesquisa foi constituída de 239 técnicos administrativos do Instituto Federal de Educação, Ciência e Tecnologia de Goiás, Instituto Federal Goiano e da Universidade Federal de Goiás. Para a coleta de dados foi utilizado um questionário sobre o perfil do servidor e o Inventário de Motivação e Significado no trabalho (IMST). Os resultados revelados pela pesquisa mostraram níveis de motivação entre os técnicos das instituições, todavia notou-se uma diferença significativa entre a força motivacional dos técnicos do Instituto Federal Goiano e das demais instituições.
\end{abstract}

Palavras-chave: motivação. Instituiçõos Federais de Ensino. Expectância.

\footnotetext{
${ }^{1}$ Doutor em Ciências do Comportamento (UNB); professor Associado (UFG/RC). E-mail: andre.silva.ufg@gmail.com

2 Mestre em gestão organizacional servidora pública federal da ufg E-mail: fcbarrosma@gmail.com
}

Artigo recebido em: 16 de março de 2018. Artigo aceito em 29 de outubro de 2018.
Key-words: Motivation. Federal Teaching Institutions. Expectation. 


\section{Introdução}

Analisar o comportamento organizacional envolve considerar as pessoas e o grupo dentro das empresas (SHEMERHORN; HUNT; OSBORN, 1998). Para a realização desse estudo Quadros e Trevisan (2002) e Mariani e Silva (2004) apontam como elementos a serem observados pelos estudiosos do comportamento organizacional nos indivíduos e nas equipes de trabalho, situações relacionadas a: atitudes, aprendizagem, liderança, mudanças nas instituições, poder, percepção, desordens, entre outros. Freire (1999) também englobou no estudo do comportamento organizacional a satisfação no trabalho e Robbin (2005), por sua vez, indicou a motivação.

Dentre esses fatores que afetam o comportamento das pessoas nas corporações, muitos autores destacam o entendimento dos construtos de motivação (EVANGELISTA; COSTA, 2008; GALHANAS, 2009; GONDIM; SILVA, 2014; JOB 2003; TAMAYO; PASCHOAL, 2003; QUEIROGA, 2009). O despertar do interesse dos estudiosos e gestores por essas percepções vem reforçar a ligação entre comportamento organizacional e desempenho na organização, pois, conforme Bonfim, Stefano e de Andrade (2010) e Campello (2010), tal avivamento ou estímulo está relacionado à importância desses construtos para o alcance da eficácia organizacional: trabalhador motivado produz mais e melhor.

Considerando essa relevância do fenômeno motivacional para as organizações, é importante ressaltar que as instituições públicas também estão inseridas nesse ambiente de mudanças no trabalho (FADUL, 1997). No âmbito dessas optou-se neste trabalho por estudar a motivação dos trabalhadores da área de educação, especificamente os técnicos administrativos das instituições federais de ensino superior, tendo em vista a importância da educação superior como instrumento de superação dos problemas sociais e econômicos (BERTOLIN, 2007; PRESTES; JEZINE; SCOCUGLIA, 2012).

É possível mensurar a motivação e a satisfação de trabalhadores e nesse sentido tem-se utilizado amplamente a Teoria de Expectância, de Vroom, para mensurar a motivação e a satisfação dos servidores técnico-administrativos ativos das instituições federais de ensino superior (IFES) do estado de Goiás. De forma específica buscou-se: a) identificar fatores que influenciam a motivação no trabalho para os técnicos administrativos em educação das instituições de ensino superior do estado de Goiás; e, b) comparar níveis de incentivo no trabalho dos técnicos administrativos entre as 


\section{SILVA; BARROS}

diferentes instituições estudadas, a partir de fatores de motivação no trabalho determinados a partir da Teoria da Expectativa.

Para alcançar o objetivo desejado se utilizou do Inventário de Motivação e Satisfação no Trabalho (IMST), que é um instrumento de mensuração do significado do trabalho do indivíduo a partir da associação de motivação e satisfação (SIQUEIRA et al, 2008). O IMST é, na verdade, uma ampliação de um outro, o IST (Inventário do Significado do Trabalho). Ambas as ferramentas se fundamentam na Teoria das Expectativas, de Vroom (1969).

A pesquisa está estruturada em cinco seções, além da Introdução: a Fundamentação Teórica, o Método, os Resultados e Discussões e por fim, as Considerações Finais.

\section{Fundamentação Teórica}

De acordo com Ferreira (2010), a motivação no trabalho é um assunto de interesse de vários estudiosos e teóricos da psicologia aplicada e também de gestores de organizações, para os quais, quando o trabalhador alcança, ou mesmo supera as metas determinadas, é importante manter a estratégia que permitiu esse nível de desempenho.

Dentre um conjunto de teorias sobre motivação, as hipóteses de processo têm sido consideravelmente investigadas. O presente trabalho busca aprofundar na Teoria da Expectância, de Victor Vroom; uma das mais utilizadas pelos estudiosos atualmente, sobretudo no Brasil (CARVALHO; SOUSA, 2007; GONDIM; SILVA, 2014). Pode-se inferir, de acordo com o entendimento de Carvalho e Sousa (2007), que a constante utilização dessa suposição está relacionada à estreita relação da teoria com o desempenho dos empregados. Constata-se que esta reflexão pode ser estendida também a servidores de instituições públicas de ensino.

Para Vroom (1995), o problema central de uma teoria sobre motivação é explicar a escolha ou a direção do comportamento do indivíduo no ambiente de trabalho. A fim de averiguar a interrelação entre o labor e a motivação, este pesquisador definiu que o estudo do trabalho em sua teoria se concentraria nos papéis de trabalho, nos quais as tarefas a serem cumpridas são determinadas por um empregador que paga salários àqueles que desenvolvem as tarefas. A motivação para esse autor está relacionada ao processo de escolhas realizadas pelas pessoas entre as várias opções de atividade voluntária. 


\section{SILVA; BARROS}

O psiquiatra e professor Víctor Vroom (1995, p.7) completa a reflexão observando que sua teoria considera as implicações das variáveis da motivação sobre o comportamento das pessoas no trabalho, bem como o efeito da atividade ou produto desenvolvido pelas pessoas sobre as variáveis motivacionais. Ele aponta como fenômenos que permearam sua pesquisa: "a escolha realizada pelas pessoas entre os papéis de trabalho; a extensão de sua satisfação com os papéis de trabalho escolhidos e o nível de seu desempenho e eficácia dentro dos papéis de trabalho escolhidos".

Em síntese, o estudioso defende que o processo que conduz à motivação encontrase alinhado àquilo que o indivíduo acredita que poderá obter com o seu desempenho no trabalho. Nessa perspectiva, a motivação resulta da relação existente entre três variáveis: a valência (refere-se a "orientações afetivas para resultados particulares"), a instrumentalidade (concepção de que o esforço realizado levará ao alcance do resultado desejado) e a expectativa (consiste na percepção de quanto o esforço conduz aos resultados esperados. É o grau no qual o indivíduo crê que um resultado específico seja provável).

Vroom (1995) ressalta ainda a importância do entendimento da diferença entre os conceitos de expectativa e de instrumentalidade: o primeiro corresponde a uma combinação entre ação e resultado, considerando valores que variam a partir de zero, a fim de que realmente um esforço proporcione determinado resultado; instrumentalidade relaciona resultado a resultado, significando a crença de que um segundo resultado será alcançado somente a partir de um primeiro resultado, que se torna condição imperativa e suficiente para a realização do segundo.

A força motivacional é definida por Vroom (1995) de acordo com o conceito de força, adotado por Lewin como o elemento que possibilita a combinação entre valências e expectativas. A partir da premissa de que as escolhas realizadas pelas pessoas são subjetivas e racionais, é possível supor que a força máxima deriva de "uma função monotônica crescente do produto de valências e expectativas" (VROOM, 1995, p.21).

Considerando essa relação entre força motivacional, valências e expectativas, Vroom (1995, p.21) apresenta a seguinte proposição: “a força de uma pessoa para realizar um ato é uma função monotônica crescente da soma algébrica dos produtos das valências de todos os resultados e a força de suas expectativas de que o ato será seguido pelo alcance destes resultados". Partindo dessa premissa, o estudioso (1995) aponta algumas implicações: à proporção que a força de uma expectativa de que um ato 


\section{SILVA; BARROS}

ocasionará determinado resultado se eleva, o efeito das variações na valência do resultado sobre a força de realizar o ato também se eleva; o oposto acontece quando a valência de um resultado é nula, na qual tanto o valor absoluto quanto as variações das expectativas de concretização dos resultados terão influência sobre as forças.

A tese defendida por Vroom, na opinião de Gondim e Silva (2014), é de que os empregados escolhem as tarefas que vão realizar de modo instrumental, buscando aumentar seu prazer e seu lucro e reduzir o desprazer e as perdas, o que ratifica a visão do psiquiatra (1995) sobre a influência do hedonismo no processo motivacional.

Ante o exposto, é possível concordar com Presti (2006) quando ele afirma que motivação é sinônimo de prosperidade. Outrossim, os estudos sobre essa questão são justificados sobretudo pela crença de que o fenômeno motivacional elucida o problema do mau e do bom desempenho (AMBROSE; KULIK, 1999) em organizações privadas, assim como nas públicas (GONDIM; SILVA, 2014).

Além de se compreender a importância das pesquisas sobre motivação no trabalho, entender o estágio das investigações atuais sobre este tema é fundamental para se dar robustez aos novos estudos nesta área. Com esse objetivo será apresentado um subtópico descrevendo o foco das investigações desenvolvidas mais recentemente sobre motivação no trabalho.

\subsection{Estudos sobre motivação no trabalho}

$\mathrm{Na}$ revisão de literatura Lathan e Pinder (2005), ao estudarem a motivação no trabalho nos primeiros anos do século XXI, destacaram o crescimento de pesquisas sobre capacidade de prever, entender e influenciar a motivação no ambiente de trabalho a partir da observação de múltiplos aspectos relacionados à motivação, como afetos, particularmente as emoções, comportamento e cognição, especialmente em relação a metas, além das necessidades e valores.

Nessa linha de pensamento recorre-se a Gondim e Silva (2014), para quem nos últimos anos os valores cada vez mais consolidam sua importância nas teorias motivacionais e as metas passaram a ser visualizadas como elementos para a realização dos valores. Gondim e Silva (2014) ainda relatam que os valores também estão presentes na Teoria da Expectância, de Vroom, na definição de valência.

Ao analisarem a questão Lathan e Kulik (2005) concluíram que, apesar do surgimento de novas suposições sobre motivação no trabalho, poucas contribuíram tanto 
para o desenvolvimento do tema quanto a Teoria das Necessidades, de Maslow; a Teoria do Estabelecimento de Metas, de Lathan e Locke, e a Teoria da Expectância, de Vroom.

No Brasil, de acordo com Gondim e Silva (2014), há três linhas de estudo sobre motivação no trabalho: a do entendimento do conceito e da classificação das teorias em de "conteúdo" ou "de processo"; a da construção de instrumentos de medida da motivação tomando como base o trabalho, a aprendizagem e a realização que sirvam para orientar os gestores na administração das organizações; e, a das investigações empíricas, para analisar as hipóteses mais estudadas no mundo, especialmente, a Teoria da Expectância.

Afora o conhecimento de pesquisas relevantes sobre a mensuração do construto motivação, como a versão mais nova do IMST (Inventário de Motivação e Satisfação no Trabalho), é relevante o entendimento do foco das investigações empíricas realizadas sobre o tema, em especial sobre a Teoria da Expectância, o que será mostrado em seguida. Nesse sentido, destacam-se: Seleção de Pessoas e desempenho no trabalho: um estudo sobre a validade preditiva dos testes de conhecimento, de Queiroga (2009); Gestão da Estratégia e Motivação: um estudo de caso na Companhia Hidro Elétrica do São Francisco - CHESF (BRITO; REGIS; MORAES, 2010); Motivação para o trabalho: um estudo de caso com profissionais de saúde das unidades básicas de saúde do município de Natal/RN; Significado e motivação no trabalho: estudo de caso em uma empresa de usinagem mecânica e caldeiraria da região dos Inconfidentes de MG (PRAZERES, 2013); e As influências na motivação para o trabalho em ambientes com metas e recompensas: um estudo no setor público (RODRIGUES; REIS NETO; GONÇALVES FILHO, 2014).

Unindo a Teoria da Expectância e uma versão adaptada do IMST, Queiroga (2009) apresenta o trabalho Seleção de Pessoas e desempenho no trabalho: um estudo sobre a validade preditiva dos testes de conhecimento. Esta tese objetivou avaliar se o desempenho dos candidatos nos testes de conhecimento aplicados durante a seleção seriam elementos preditores dos níveis de desempenho desses candidatos quando eles estivessem trabalhando. Nesse estudo uma das variáveis observadas foi a motivação do candidato para o trabalho. A coleta dos dados foi realizada por meio de uma adaptação da versão do IMST, de Borges, Alves Filho e Tamayo (2008), considerando somente os itens do IMST relacionados à motivação. Foram testadas as características 


\section{SILVA; BARROS}

psicométricas dessa versão, que passou a ter 32 itens, envolvendo as dimensões valência, instrumentalidade e expectativa do construto motivação. Após a demonstração da confiabilidade do modelo produzido foi analisada a relação entre motivação e desempenho e demostrada uma relação positiva quanto à autopercepção dos indivíduos. Contudo, essa observação não teve correlação com as avaliações de desempenho realizadas pelas organizações, nem entre motivação e percepção de suporte organizacional, pois esta hipótese não foi unânime nas organizações pesquisadas.

Outro estudo que adotou a Teoria das Expectativas como referência teórica sobre motivação foi Gestão da Estratégia e Motivação: um estudo de caso na Companhia Hidro Elétrica do São Francisco - CHESF (BRITO; REGIS; MORAES, 2010). O estudo teve o intuito de verificar a correlação existente entre motivação, a partir da Teoria da Expectância e gestão estratégica. A coleta de dados ocorreu entre os gestores da Companhia Hidroelétrica do São Francisco, após o preenchimento de escala de recompensa. Os autores verificaram que há uma correlação entre motivação, sob a égide da Teoria da Expectância, e gestão estratégica, por meio do PDCA ${ }^{1}$. Ademais, os pesquisadores chamaram a atenção para a necessidade de aprofundamento das investigações com esse enfoque e ressaltaram a importância dos debates sobre as recompensas associadas à motivação.

Continuando os estudos sobre motivação a partir da Teoria da Expectativa, Alves Filho (2012) apresentou a dissertação Motivação para o trabalho: um estudo de caso com profissionais de saúde das unidades básicas de saúde do município de Natal/RN. Nessa inquirição buscou-se averiguar a motivaçaõ dos profissionais de saúde das unidades básicas de saúde do município de Natal/RN, baseando-se nos conceitos da Teoria da Expectância, de Vroom (1995), a saber: resultados do trabalho, expectativa, valência, instrumentalidade e força motivacional. Como instrumentos de coleta de dados utilizou-se o IMST e entrevistas com questões sobre o mesmo assunto, a fim de confrontar os resultados dos dados dos dois tipos de coleta.

Após as análises dos dados verificou-se que houve simetria entre os resultados apresentados pelo IMST e pelas entrevistas, que apontaram como fatores motivadores para os participantes da pesquisa: a autoexpressão e realização pessoal e sobrevivência pessoal e familiar, em valência; os fatores autoexpressão e justiça no trabalho, segurança e dignidade e responsabilidade, em relação à expectativa; em

${ }^{1}$ PDCA Plan, Do, Check, Action (Planejar, Fazer, Verificar e Agir) 


\section{SILVA; BARROS}

instrumentalidade, destacaram-se os fatores envolvimento e reconhecimento $\mathrm{e}$ independência econômica. Como fatores redutores da força motivacional a pesquisa registrou desgaste e desumanização em valência, expectativa e instrumentalidade, além de injustiça no trabalho. Como conclusão a investigação mostrou que a força motivacional dos participantes da pesquisa é moderada e está em declínio, em virtude das condições desfavoráveis do ambiente de trabalho.

Outro estudo sobre motivação no trabalho sob a perspectiva teórica da Teoria da Expectância foi desenvolvido por Prazeres (2013): Significado e motivação no trabalho: estudo de caso em uma empresa de usinagem mecânica e caldeiraria da região dos Inconfidentes de MG. O objetivo principal deste estudo: identificar e mensurar o significado do trabalho e da motivação para os empregados dessa empresa. Como objetivos específicos da pesquisa o autor pretendeu também mensurar indicadores do significado no trabalho e de motivação no trabalho, com base no IMST (BORGES; ALVES FILHO, 2001), bem como analisar a existência de relação entre os dois construtos, a partir da mensuração e verificação dos dados dos fatores dos construtos no IMST (BORGES; ALVES FILHO, 2001) e identificar e analisar os fatores motivacionais e do significado do trabalho na empresa pesquisada.

Os resultados encontrados na pesquisa demonstraram situação moderada na maior parte dos indicadores observados nas escalas dos construtos e a existência de correlação entre os construtos estudados. Todavia, o autor notou em fatores relacionados ao significado do trabalho que os empregados mantêm um certo grau de insatisfação que necessita ser melhorado, pois os trabalhadores percebem o labor como sinônimo de esforço excessivo, subordinação hierárquica, alienação, alta produtividade e necessidade de recompensa econômica.

Ainda sobre a concepção de Teoria da Expectativa, os fatores motivadores e o serviço público, tem-se o artigo As influências na motivação para o trabalho em ambientes com metas e recompensas: um estudo no setor público (RODRIGUES; REIS NETO; GONÇALVES FILHO, 2014). Nessa pesquisa investigou-se as influências da motivação para o trabalho de servidores públicos. Utilizou-se um questionário com perguntas fechadas para coleta de dados, a fim de medir, conforme Rodrigues, Reis Neto (2014), a especificidade, a dificuldade e a relevância das metas; a participação na determinação das metas e o retorno sobre o alcance das metas, a autoeficácia. Buscou-se ainda dimensionr a avaliação geral do sistema de metas e recompensas, a expectativa, a 


\section{SILVA; BARROS}

instrumentalidade, a equidade, a valência das recompensas externas, a valência da missão e a motivação para o trabalho.

Para a identificação do perfil dos servidores participantes da pesquisa foram aplicadas questões sobre idade, sexo, estado civil, tipo de remuneração (fixa ou variável), salário, tempo de serviço, vínculo empregatício, posição hierárquica e nível de escolaridade. Para análise dos dados, utilizou-se a verificação fatorial exploratória com extração por componentes principais, para examinar a unidimensionalidade dos contrutos e a técnica de modelagem de equações estruturais. Para avaliar as propriedades psicométricas das medidas e o método Chaid, e investigar como as características individuais se relacionam com as metas, as recompensas e a motivação, no qual as características demográficas considerou-se variáveis independentes e os construtos variáves dependentes.

Como resultado foram apontados: a) como fatores motivadores diretos dos funcionários públicos: a valência da missão da instituição, a instrumentalidade relacionada às recompensas e autoeficácia no alcance das metas; b) como fatores que influenciaram a motivação de forma importante, mas indireta: a especificidade e o feedback em relação às metas. Ademais, os funcionários de faixa etária mais alta foram os que apresentaram maiores médias de motivação. Os servidores ocupantes de cargos mais elevados hierarquicamente ou que recebiam recompensa extra pelo trabalho apresentaram os maiores índices de motivação, considerando-se fatores que afetam a motivação positiva ou negativamente. Esses resultados ratificaram a influência das metas e recompensas na motivação para o trabalho. Além disso, a pesquisa mostrou que os objetivos e recompensas também são fatores motivadores para os funcionários públicos.

Ante o exposto faz-se necessário esclarecer que a presente pesquisa visa investigar a motivação no trabalho sob a perspectiva da Teoria da Expectância, de Victor Vroom (1995), totalmente justificada pela constante utilização dessa hipótese nos últimos anos, como se pôde confirmar pelos estudos citados acima. Outrossim, considerando que a tendência dos estudos sobre motivação no Brasil é buscar desenvolver instrumentos para mensurar a motivação no trabalho, esta pesquisa tem o propósito de medir a motivação em um ambiente de trabalho utlizando como instrumento o IMST, já aperfeiçoado várias vezes como demonstrado nos estudos elencados anteriormente. Além disso, este trabalho se propõe a estudar a motivação no trabalho na administração 
pública, também foco de pesquisas recentes sobre o construto.

\section{Método}

\subsection{Descrição do local da pesquisa}

Nesta pesquisa foram envolvidas três instituições federais do estado de Goiás: a) Universidade Federal de Goiás (UFG), conforme disposto no Artigo 13 de seu estatuto se estrutura em vários campi organizados em cinco regionais (BRASIL, 2014a); b) Instituto Federal de Educação, Ciência e Tecnologia de Goiás (IFG), com 13 campi em funcionamento (BRASIL, 2014b); Instituto Federal Goiano (IF Goiano), que dispõe de seis campi (BRASIL, 2014c).

\subsection{População e amostra}

O universo de estudo desta investigação focou os servidores técnicoadministrativos em educação ativos das instituições de ensino superior (IES) federais do estado de Goiás: Universidade Federal de Goiás, que possui 2.395 trabalhadores; Instituto Federal de Educação, Ciência e Tecnologia de Goiás, que conta com 704 técnico-administrativos; e Instituto Federal Goiano, com 424 técnico-administrativos em educação (TAEs).

Participaram da pesquisa 255 servidores técnico-administrativos, entretanto somente o total de 239 questionários válidos será considerado. Todos os servidores receberam convites para participar da enquete e a adesão ao estudo se deu de forma espontânea e voluntária. O convite foi feito por duas vezes, com intervalo de duas semanas.

\subsection{Instrumento de coleta de dados}

Para o desenvolvimento deste estudo utilizou-se o Termo de Consentimento Livre Esclarecido (TCLE), com informações gerais sobre a pesquisa, que foi entregue à todos os participantes, em seguida solicitou-se aos participantes que respondessem o Inventário de Motivação e Significado do Trabalho (IMST). Este instrumento de coleta de dados é utilizado para o entendimento da motivação e significado do trabalho, à luz da Teoria das Expectativas de Vroom (BORGES; ALVES FILHO; TAMAYO, 2008).

O IMST, em sua versão mais atual, apresenta como estrutura fatorial: para a 
mensuração do significado no trabalho utiliza-se os atributos valorativos (alfa entre 0,78 e 0,91 ) e descritivos (alfa entre 0,74 e 0,83 ) e para medir motivação, itens relacionados à expectativas (alfa entre 0,82 e 0,87) e instrumentalidade (alfa entre 0,70 e 0,87) (BORGES; ALVES FILHO; TAMAYO, 2008).

\subsection{Procedimento de coleta de dados}

Para a coleta de dados inicialmente foram enviadas cartas às IES federais do estado de Goiás, solicitando autorização para a realização da pesquisa. Em seguida, a proposta foi encaminhada para apreciação do Comitê de Ética em Pesquisa da UFG. Com a aprovação da proposta pelo Comitê de Ética, sob o Parecer n ${ }^{\circ} 713.315$, de 07 de julho de 2014, novo contato foi realizado junto às instituições participantes, solicitando o e-mail dos servidores técnico- administrativos ativos para o envio do resumo e do link da pesquisa, bem como informá-los do prazo (de 13 de julho a 30 de setembro de 2014) para a participação individualizada no estudo, via google docs.

\section{Resultados e discussão}

Para facilitar a apresentação dos resultados sobre motivação no trabalho e a discussão dos mesmos, as conclusões do IMST nos atributos Expectativas e Instrumentalidade, bem como da Força motivacional, organizou-se as resultantes obtidas com a utilização do IMST pela análise da distribuição percentual entre as classes de escores por dimensão, por fator em cada dimensão e pelo cálculo da Força motivacional.

Os resultados obtidos a partir da análise do percentual dos escores estão demonstrados na Tabela 2.

Tabela 2 - Distribuição percentual dos escores das dimensões do IMST

\begin{tabular}{|c|c|c|c|c|c|c|c|}
\hline \multirow[b]{2}{*}{ Dimensão } & \multirow[b]{2}{*}{ Fator } & & \multicolumn{4}{|c|}{ Percentual das classes } & \multirow{2}{*}{$\begin{array}{c}\mathrm{p}- \\
\text { Fisher }\end{array}$} \\
\hline & & & $\leq 1$ & $>1 \mathrm{e} \leq 2$ & $>2$ e $\leq 3$ & $>3$ & \\
\hline \multirow[t]{9}{*}{ Expectativas } & Autoexpressão & IF & 5,6 & 8,3 & 55,6 & 30,6 & 0,5145 \\
\hline & FE1 & IFG & 0,0 & 21,2 & 60,6 & 18,2 & \\
\hline & & UFG & 3,2 & 19,0 & 52,5 & 25,3 & \\
\hline & Desgaste e & IF & 2,8 & 36,1 & 61,1 & 0,0 & 0,0059 \\
\hline & Desumanização & IFG & 3,0 & 51,5 & 45,5 & 0,0 & \\
\hline & FE2 & UFG & 1,3 & 27,8 & 58,2 & 12,7 & \\
\hline & Responsabilidade & IF & 0,0 & 8,3 & 16,7 & 75,0 & 0,4668 \\
\hline & FE3 & IFG & 0,0 & 3,0 & 27,3 & 69,7 & \\
\hline & & UFG & 0,0 & 6,3 & 31,0 & 62,7 & \\
\hline
\end{tabular}

Revista Eletrônica Gestão e Serviços v.9, n. 2, pp. 2473-2495, julho/dezembro 2018. ISSN Online: 2177-7284 e-mail: regs@metodista.br 
SILVA; BARROS

\begin{tabular}{|c|c|c|c|c|c|c|c|}
\hline & $\begin{array}{l}\text { Independência } \\
\text { Econômica } \\
\text { FE4 }\end{array}$ & $\begin{array}{l}\text { IF } \\
\text { IFG } \\
\text { UFG }\end{array}$ & $\begin{array}{l}0,0 \\
0,0 \\
1,3\end{array}$ & $\begin{array}{l}0,0 \\
6,1 \\
8,2\end{array}$ & $\begin{array}{l}33,3 \\
42,4 \\
58,2\end{array}$ & $\begin{array}{l}66,7 \\
51,5 \\
32,3\end{array}$ & 0,0080 \\
\hline & Segurança e & IF & 11,1 & 2,8 & 41,7 & 44,4 & 0,0006 \\
\hline & Dignidade & IFG & 3,0 & 15,2 & 42,4 & 39,4 & \\
\hline & FE5 & UFG & 5,7 & 23,4 & 50,6 & 20,3 & \\
\hline \multirow[t]{15}{*}{ Instrumentalidade } & \multirow{3}{*}{$\begin{array}{l}\text { Envolvimento e } \\
\text { reconhecimento } \\
\text { FI1 }\end{array}$} & IF & 2,9 & 8,6 & 37,1 & 51,4 & 0,7820 \\
\hline & & IFG & 0,0 & 18,8 & 46,9 & 34,4 & \\
\hline & & UFG & 2,5 & 13,2 & 42,8 & 41,5 & \\
\hline & \multirow{3}{*}{$\begin{array}{l}\text { Condições mate- } \\
\text { riais de trabalho } \\
\text { FI2 }\end{array}$} & IF & 0,0 & 25,7 & 37,1 & 37,1 & \multirow[t]{3}{*}{0,0950} \\
\hline & & IFG & 9,4 & 25,0 & 31,3 & 34,4 & \\
\hline & & UFG & 3,1 & 24,5 & 49,7 & 22,6 & \\
\hline & \multirow{2}{*}{$\begin{array}{l}\text { Desgaste e } \\
\text { Desumanização }\end{array}$} & IF & 0,0 & 38,2 & 55,9 & 5,9 & \multirow[t]{3}{*}{0,0243} \\
\hline & & IFG & 15,6 & 53,1 & 25,0 & 6,3 & \\
\hline & FI3 & UFG & 4,4 & 35,8 & 49,7 & 10,1 & \\
\hline & \multirow{3}{*}{$\begin{array}{l}\text { Recompensa e } \\
\text { independência } \\
\text { econômica - FI4 }\end{array}$} & IF & 0,0 & 5,7 & 11,4 & 82,9 & \multirow[t]{3}{*}{0,2086} \\
\hline & & IFG & 0,0 & 0,0 & 31,3 & 68,8 & \\
\hline & & UFG & 0,0 & 3,1 & 26,4 & 70,4 & \\
\hline & \multirow{3}{*}{$\begin{array}{l}\text { Responsabilidade } \\
\text { FI5 }\end{array}$} & IF & 0,0 & 11,4 & 37,1 & 51,4 & \multirow[t]{3}{*}{0,4127} \\
\hline & & IFG & 6,3 & 9,4 & 43,8 & 40,6 & \\
\hline & & UFG & 0,6 & 10,1 & 46,5 & 42,8 & \\
\hline \multirow{4}{*}{$\begin{array}{l}\text { Força } \\
\text { motivacional }\end{array}$} & \multirow{4}{*}{ FM } & & $\leq 64$ & $>64$ e $\leq 128$ & $>128$ e $\leq 192$ & $>192$ & \multirow{4}{*}{$<0,0001$} \\
\hline & & IF & 15,2 & 3,0 & $69, \overline{7}$ & 12,1 & \\
\hline & & IFG & 3,1 & 56,3 & 34,4 & 6,3 & \\
\hline & & UFG & 9,9 & 45,0 & 39,7 & 5,3 & \\
\hline
\end{tabular}

Fonte: elaboração própria.

Observando a Tabela 2, na dimensão Expectativa e levando em consideração o percentual das classes, observa-se no fator Autoexpressão que para as três instituições pesquisadas a maior parte dos participantes da enquete se encontra no intervalo de $>2 \mathrm{e}$ $\leq 3$. Para o IF Goiano, após a concentração de indivíduos nesse intervalo, os demais servidores se aglomeram em maior quantidade no intervalo $>3$ e em menores proporções no intervalo $>1 \mathrm{e} \leq 2 \mathrm{e} \leq 1$. Para o IFG, os demais técnicos se subdividem entre os intervalos $>1$ e $\leq 2$ e $>3$. Na UFG, o restante dos servidores se distribui em maior quantidade pelos $>3$ e $>1$ e $\leq 2$ e em número menor ocupa o intervalo $\leq 1$. Notase também nesse fator que não há diferença significativa entre os resultados apresentados pelas instituições.

Para o fator Desgaste e desumanização, analisando-se os resultados da Tabela 2 sob a ótica do percentual de classes, verifica-se que para o IF Goiano a maior parte dos técnicos administrativos se encontra no intervalo de escore $>2$ e $\leq 3$, e em seguida, com menor proporção $\leq 2$ e $\leq 1$ e em número bem reduzido, ocupa o intervalo $>1$. Não há servidores no intervalo $>3$. Para o IFG, a maior parte dos participantes se encontra no intervalo de escore inferior $>1$ e $\leq 2$ e quase o mesmo percentual de servidores se encontra no intervalo $>2$ e $\leq 3$, ficando um percentual bem menor de servidores no 


\section{SILVA; BARROS}

intervalo $\leq 1$. Para a UFG, a maior parte dos técnicos administrativos se encontra no intervalo de escore $>2$ e $\leq 3$, e em seguida, com menor proporção, os servidores estão distribuídos nos intervalos $>1$ e $\leq 2,>3$ e um número bem reduzido no intervalo $\leq 1$. Quanto ao grau de relevância das diferenças entre as instituições, observa-se diferença significativa.

Quanto ao fator Responsabilidade, observando a Tabela 2 no percentual das classes, nota-se que a maior parte dos técnicos no IFG se encontra no intervalo $>3$ e que o restante está subdividido, em menor proporção, entre os intervalos $>2$ e $\leq 3$ e $>1$ e $\leq$ 2. Quanto aos técnicos do IFG verifica-se que a maioria também se posiciona no intervalo $>3$ e, em proporções bem menores, nos intervalos $>2$ e $\leq 3$ e $>1$ e $\leq 2$. Para a UFG, a maior parte dos técnicos se concentra no intervalo $<3$, seguida de uma ocupação reduzida de técnicos nos intervalos $>2$ e $\leq 3$ e $>1$ e $\leq 2$. Não há diferença significativa entre os resultados apresentados pelas instituições.

Quanto à observação dos fatores da Instrumentalidade pelo percentual de classes na Tabela 2, nota-se que para o fator Envolvimento e reconhecimento a maior parte dos participantes da pesquisa pelo IF Goiano se encontra no intervalo de escore > 3, seguida da ocupação em menor proporção do intervalo $>2$ e $\leq 3$, e em número bem menor nos intervalos $>1$ e $\leq 2$ e $\leq$ 1. Para a UFG, os técnicos administrativos ocupam em maior quantidade o intervalo $>2$ e $\leq 3$ e em proporções menores os $>3,1$ e $\leq 2$ e $\leq 1$. Pelo p-value apresentado na Tabela 2, em relação a esse fator, nota-se diferença significativa entre os resultados evidenciados pelas instituições pesquisadas.

Para o fator Condições materiais de trabalho, pelo percentual das classes, verificase que para o IF Goiano o maior número de respondentes está no intervalo $>3$, seguidos de uma concentração um pouco menor de servidores no intervalo $>2$ e $\leq 3$ e em quantidade inferior nos intervalos $\leq 1 \mathrm{e}>1 \mathrm{e} \leq 2$. Para o IFG, a maior parte dos servidores se concentra no intervalo $>2$ e $\leq 3$ e em seguida, em número um pouco menor ocupam o intervalo $>3$ e os demais se distribuem nos intervalos $>1$ e $\leq 2$ e $\leq 1$. Na UFG, para esse fator, a maior parte dos servidores se concentra no intervalo $>2$ e $\leq 3$, seguida dos intervalos $>3,>1$ e $\leq 2$ e $\leq 1$. Também verifica-se que há diferença significativa entre os resultados apresentados pelos técnicos das instituições pesquisadas.

Quanto à observação dos fatores da Instrumentalidade pelo percentual de classes 


\section{SILVA; BARROS}

na Tabela 2 constata-se que para o fator Envolvimento e reconhecimento a maior parte dos participantes da pesquisa pelo IF Goiano se encontra no intervalo de escore $>3$, seguida da ocupação em menor proporção dos intervalos $>2$ e $\leq 3$ e $>1$ e $\leq 2$, em número bem menor do intervalo $\leq 1$. A maior parte dos participantes pelo IFG se concentra no intervalo $>2$ e $\leq 3$ e os demais, distribuídos nos intervalos $>3$ e $>1$ e $\leq 2$. $\mathrm{Na}$ UFG a maior parte dos participantes também se encontra no intervalo $>2$ e $\leq 3$, seguida de ocupação um pouco menor no intervalo $>3$ e bem menor no $\mathrm{s}$ intervalos $>1$ $\mathrm{e} \leq 2 \mathrm{e} \leq 1$

Quanto ao fator Condições materiais de trabalho, para o IF Goiano o maior percentual de servidores se encontra igualitariamente distribuído entre os escores $>2$ e $\leq 3$ e $<3$ e o restante, no intervalo $>1$ e $\leq 2$. Para o IFG os maiores percentuais de servidores se concentram no intervalo $<3$ e $>2$ e $\leq 3$, com percentual ligeiramente menor no escore $>1$ e $\leq 2$ e uma quantidade menos representativa no escore $\leq 1$. Para a UFG quase metade dos técnicos ocupa o intervalo $>2$ e $\leq 3$, estando os demais servidores distribuídos entre os intervalos $>3$ e $>1$ e $\leq 2$, e em número bem inferior no intervalo $\leq 1$.

Para o fator Desgaste e desumanização observa-se na Tabela 2 que mais da metade dos servidores participantes da pesquisa pelo IF Goiano se encontra no intervalo $>2$ e $\leq 3$ e os demais se posicionam em maior número no intervalo $>1$ e $\leq 2$ e em quantidade inferior no intervalo $>3$. Quanto ao IFG, mais da metade dos técnicos participantes da pesquisa por esta instituição, se encontra no intervalo $>1$ e $\leq 2$ e os demais estão distribuídos pelos intervalos $>2$ e $\leq 3$ e $\leq 1$, e em número inferior, pelo intervalo >3. Para a UFG, nota-se que a maior parte dos servidores se concentra no intervalo $>2$ e $\leq 3$, em número um pouco menor no intervalo $>1$ e $\leq 2$ e em números menores ainda, respectivamente nos intervalos $>3 \mathrm{e} \leq 1$.

No fator Recompensas e independência econômica observa-se na Tabela 2 que quase $83 \%$ dos servidores do IF Goiano se encontra no intervalo $>3$ e os demais estão distribuídos entre os intervalos $>2$ e $\leq 3$ e $>1$ e $\leq 2$. No IFG, quase $70 \%$ dos servidores se encontra no intervalo > 3 e os demais se, distribuídos no intervalo $>2$ e $\leq 3$. Para a UFG nota-se que um pouco mais que $70 \%$ dos técnicos se encontra no intervalo $>3$ e os demais estão distribuídos entre os intervalos $>2$ e $\leq 3$ e em menor número no 
intervalo $>1 \mathrm{e} \leq 2$

Quanto ao fator Responsabilidade, na Tabela 2, tomando como base o percentual de classes, verifica-se no IF Goiano que pouco mais da metade dos técnicos se concentra no intervalo $>3$ e a outra metade, distribuída nos intervalo $>2$ e $\leq 3$ e $>1$ e $\leq$ 2. No IFG, a maior parte dos técnicos se encontra no intervalo $>2$ e $\leq 3$ e um proporção um pouco menor de técnicos no intervalo $>3$, os demais $18 \%$ restantes se encontram distribuídos nos intervalos $>1$ e $\leq 2$ e $\leq 1$. Na UFG nota-se que 46,5\% dos técnicos se encontram no intervalo $>2$ e $\leq 3$ e $42,8 \%$ no intervalo $>3$, enquanto os demais estão distribuídos entre os intervalos $>1$ e $\leq 2$ e em menor proporção no intervalo $\leq 1$.

Analisando os p-values apresentados na Tabela 2, para os fatores da dimensão instrumentalidade verifica-se que a distribuição percentual entre as três instituições participantes da pesquisa é desigual no fator Desgaste e desumanização.

Observando a Força Motivacional, na Tabela 2, verifica-se que quase $70 \%$ dos participantes da pesquisa para o IF Goiano se encontra no intervalo $>128$ e $\leq 192$, enquanto os demais técnicos estão distribuídos nos intervalos $\leq 64, \leq 256$ e $>64$ e $\leq 128$. Para o IFG, quase $57 \%$ dos técnicos está no intervalo $>64$ e $\leq 128,39,7 \%$ no intervalo $>128$ e $\leq 192$ e os demais distribuídos nos intervalos $\leq 256$ e $\leq 64$. Na UFG, percebe-se que a maior parte dos técnicos se concentra no intervalo $>64$ e $\leq 128$ e um percentual somente um pouco menor no intervalo $>128$ e $\leq 192$, sendo que aproximadamente $15 \%$ se encontram distribuídos nos intervalos $\leq 64$ e $\leq 256$.

Quanto ao grau de significância da diferença entre os resultados apresentados pela Força motivacional entre os técnicos participantes da pesquisa na Tabela 2 nota-se, pelo p-value apresentado, que há diferença significativa entre as instituições. Após a descrição dos resultados da Tabela 2 é importante relatar o que pode ser entendido pela análise da mesma.

Analisando os fatores motivacionais nas Expectativas, a partir da frequência dos técnicos administrativos por intervalos da distribuição de escores (0-4), verifica-se que há poucas diferenças entre a frequência dos técnicos administrativos nestes fatores nas três instituições, com destaque para o fator Desgaste e desumanização, no qual o IFG apresenta um percentual maior de servidores no escore $>1 \mathrm{e} \leq 2$, se comparado às demais instituições pesquisadas e melhor também que os resultados apresentados por Alves Filho (2012), nos quais a maior parte dos participantes da pesquisa se encontra no intervalo $>2$ e $\leq 3$. Isso demonstra que os técnicos do IFG estão menos propensos a 


\section{SILVA; BARROS}

visualizar o trabalho, seguindo o conceito deste fator para Borges, Alves Filho e Tamayo (2008), como fonte de cansaço, atarefamento, esforço e de sentimento de não ser humano, mas uma máquina.

Continuando a análise dos resultados dos itens relativos à Expectativa, a partir do percentual dos escores observou-se que na UFG nos fatores Recompensas e independência econômica e Condições materiais de trabalho a frequência maior dos servidores está no intervalo de escore $>2$ e $\leq 3$. Esse resultado é distinto do alcançado por Alves Filho (2012) sobre estes fatores na mesma condição de análise, resumidos na estrutura fatorial adotada pelo autor em único fator chamado Segurança e Dignidade, pois a maior parte dos respondentes se concentra no intervalo $>3$.

No geral, a análise de percentual de escores entre as classes indicou que os fatores Responsabilidade e Recompensas e independência econômica do componente motivacional Expectativa tiveram as melhores avaliações. Esse resultado, porém, é oposto ao encontrado na pesquisa realizada por Alves Filho (2012), na qual o fator que concentra mais servidores é Autoexpressão e justiça no trabalho, análogo na versão do IMST utilizada nesta pesquisa a Autoexpressão e Condições materiais de trabalho, conforme definições de Borges, Alves Filho e Tamayo (2008), e somente depois aparecem Segurança e dignidade e responsabilidade.

Seguindo a comparação entre as instituições pesquisadas sob a perspectiva da frequência dos intervalos dos escores, ressalta-se entre os fatores da Expectativa que houve diferenças significativas entre as instituições somente para as dimensões Desgaste e desumanização, Recompensas e Independência Econômica e Condições materiais de trabalho. Para o fator Desgaste e desumanização os técnicos do IF Goiano e da UFG se concentraram mais no intervalo de escores $<3$ e os servidores do IFG no intervalo $>1$ e $\leq 2$, em oposição aos resultados de Alves Filho (2012) sobre este fator, nos quais a maior parte dos servidores da pesquisa está englobada no escore $2<3$.

Considerando os fatores Recompensas e independência econômica e Condições materiais de trabalho, tem-se que a maior parte dos técnicos dos institutos federais está no escore $<3$; todavia os servidores da UFG se concentraram mais no escore $2<3$. Confrontando esses resultados com os resultados apresentados na pesquisa de Alves Filho (2012) percebe-se uma similaridade com o resultado da UFG, considerando que esses dois fatores na estrutura fatorial do instrumento adotada por Alves Filho (2012) seriam resumidos ao fator Segurança e Dignidade. 


\section{SILVA; BARROS}

No que se relaciona à instrumentalidade, analisada pelo percentual das classes, verifica-se poucas diferenças entre os percentuais das três instituições. Todavia, observa-se que no geral o fator Recompensas e independência econômica teve as melhores avaliações, contrapondo-se ao resultado da pesquisa de Alves Filho (2012), na qual o fator que obteve escores mais elevados foi o Envolvimento.

Nota-se também que somente houve diferença significativa nos elementos do componente Instrumentalidade entre as instituições para $\mathrm{o}$ fator Desgaste $\mathrm{e}$ desumanização, que para o IF Goiano, a maior parte dos técnicos administrativos se encontrava no intervalo mais elevado $(<3)$, no IFG, no intervalo $>1$ e $\leq 2$ e no IF Goiano e UFG no intervalo $>2$ e $\leq 3$. No estudo de Alves Filho (2012) a maior parte dos servidores se encontrou no escore $2<3$.

Observou-se ainda no fator Condições materiais de trabalho como elemento da Instrumentalidade que a maioria dos técnicos da UFG se concentrou no intervalo dos escores $>2$ e $\leq 3$, indicando que estes participantes da pesquisa percebiam bem menos que o seu desempenho poderia gerar melhores condições de trabalho que os demais servidores das outras instituições pesquisadas. No estudo de Alves Filho (2012), os resultados para este fator, na versão utilizada para o autor mais próximo do conceito Justiça no trabalho, verifica-se que o grau de percepção dos investigados é um pouco mais baixo para este fator $(>1 \mathrm{e} \leq 2)$.

Em síntese, apesar das diferenças entre as instituições relativas a um ou outro fator dentro dos componentes Expectativa e Instrumentalidade, pode-se concluir que, de forma geral, os principais aspectos responsáveis pelo aumento da força motivacional são Recompensas e independência econômica e Responsabilidade. O resultado sobre o fator Recompensa e independência econômica como elemento motivador é semelhante ao encontrado na pesquisa realizada por Alves Filho e Araújo (2001), após a realização das equivalências de definições com os fatores do IMST utilizados na presente pesquisa. Todavia, nas pesquisas de Borges e Alves Filho (2012) e Prazeres (2013), Recompensas e independência econômica não são os principais elementos impulsionadores da força motivacional.

Ainda refletindo sobre os dados obtidos na pesquisa sobre o fator motivador Recompensas e independência econômica pode-se inferir uma contradição com o relato de Tamayo e Paschoal (2003), que informaram que a tendência moderna para motivar trabalhadores nas organizações é de substituir a política da recompensa pelo 


\section{SILVA; BARROS}

desempenho pelo estímulo ao bem-estar e a felicidade do empregado.

Em relação aos fatores de redução da força motivacional, percebe-se unanimidade entre as instituições ao apontarem o fator Desgaste e desumanização, apesar de o IFG apresentar índices menores para este aspecto. Em pesquisa realizada por Prazeres (2013), também utilizando o IMST em seu estudo, apesar de este fator ser apontado como desmotivador, o autor aponta, dentro do componente expectativa, recompensa e independência econômica e dentro da Instrumentalidade, destaca o fator Envolvimento e reconhecimento.

Observando os resultados apresentados na Tabela 2, em relação à Força motivacional, nota-se que a maior parte dos técnicos do IF Goiano encontra-se concentrada no intervalo de moderado superior de FM. Esse resultado para força motivacional encontrado na pesquisa é próximo ao encontrado na investigação de Borges e Alves Filho (2001), realizada entre bancários e profissionais de saúde de Natal, e de Pereira (2008), que teve como amostra bancários da cidade de Brasília, nas quais sobressaiu-se a força motivacional moderada superior. No trabalho de Alves Filho (2012), também com estudantes profissionais de saúde, a maior parte dos participantes da pesquisa se encontrava no intervalo da força motivacional moderada superior.

Quanto às diferenças significativas encontradas na Tabela 2, a explicação para esta variação da força motivacional entre as instituições pesquisadas é difícil de ser explicada quando consideramos que nas instituições pesquisadas os recursos humanos seguem a mesma legislação, a Lei $\mathrm{n}^{\circ}$ 8.112/90, que trata do regime jurídico dos servidores públicos civis da União, das autarquias e das fundações públicas federais (BRASIL, 1990) possuem o mesmo plano de cargos e salários regulamentado pela Lei $\mathrm{n}^{\circ} 11.091 / 2005$ (BRASIL, 2005), bem como nos resultados dessa pesquisa, não pode ser observado grandes discrepância entre as médias e percentuais nos escores dos fatores da Expectativa e Instrumentalidade, com exceção da média no fator Desgaste e desumanização.

Independente da estrutura ou das regras adotadas em uma instituição é importante lembrar que motivação, de acordo com Vroom (1995), está relacionada aos objetivos e às escolhas individuais, bem como às expectativas de cada um em alcançar esses objetivos. Gondim e Silva (2014), parafraseando Vroom (1995), relatam motivação como força emocional e consciente acionada quando alguém precisa escolher entre vários planos de ação, estando esta força relacionada às expectativas individuais e ao 
julgamento subjetivo das implicações esperadas a partir da comparação entre as várias opções de ação.

\section{Considerações Finais}

O presente artigo foi elaborado com o objetivo principal de mensurar a motivação no trabalho dos técnicos administrativos das instituições federais de ensino superior do estado de Goiás, adotando com referencial teórico para o primeiro construto a Teoria da Expectância, de Vroom.

A fim de tornar mais compreensível tais resultados este trabalho também se preocupou em observar fatores de motivação e desmotivação entre os técnicos administrativos das instituições pesquisadas, comparar os níveis de motivação dos TAEs nestas instituições.

Assim, partindo da perspectiva da Teoria da Expectância, de Vroom, utilizou-se o Inventário de Motivação e Significado no trabalho, na versão de Borges, Alves Filho e Tamayo (2008) para coleta de dados para o construto motivação laboral. Sob o ponto de vista da mensuração geral desse fenômeno observa-se um percentual de motivação alto para os técnicos administrativos das IFES, uma vez que a maior parte dos servidores se encontra no intervalo de motivação moderado superior. Verificou-se que são aspectos motivadores para os TAEs, na dimensão Expectativa, os fatores Responsabilidade e Recompensas e independência econômica, e para a dimensão Instrumentalidade os fatores são os mesmos, porém, com o elemento Recompensas e independência econômica se destacando mais que o Responsabilidade. São fatores gerais de redução da motivação nas instituições, o elemento Desgaste e desumanização para as todas as dimensões do IMST para o fenômeno motivacional. Recomenda-se, por fim, a realização de estudo que compare outras variáveis a fim de otimizar a interpretação do modelo em situações pontuais de serviços públicos.

\section{Referências Bibliográficas}

ALVES FILHO, A. Motivação para o trabalho: um estudo com os profissionais de saúde nas unidades básicas de saúde do município de Natal-RN. 2012197 f. Tese (Doutorado em Psicologia). Universidade Federal do Rio Grande do Norte, Natal. Universidade Federal do Rio Grande do Norte, 2012.

AMBROSE, M. L.; KULIK, C. T.; Carol T. Old friends, new faces: motivation research in the 1990s. Journal of Management, v. 25, n.3, p. 231-292. 1999. 
Disponível em: https://journals.sagepub.com/toc/joma/25/4. Acesso em: Acesso em: 12. out. 2014.

BERTOLIN, J. C. G. Avaliação da qualidade do sistema de educação superior brasileiro em tempos de mercantilização - período 1994-2003. 2009. 282 f. Tese (Doutorado em Educação) - Faculdade de Educação. Universidade Federal do Rio Grande do Sul, Porto Alegre, 2007.

BONFIM, T. M.; STEFANO, S. R.; ANDRADE, S. M. Satisfação e motivação no trabalho dos servidores públicos de uma prefeitura de pequeno porte do estado do Paraná: uma análise a partir do clima organizacional. In: SEMINÁRIOS EM ADMINISTRAÇÃO, 13, 2010, São Paulo. Anais... São Paulo: FEA-USP, 2010.

BORGES, L. O. \& ALVES FILHO, A. A mensuração da motivação e do significado do trabalho. Estudos de Psicologia, n. 6, p. 177-194. 2001. Disponível em: http://www.scielo.br/pdf/epsic/v6n2/7272.pdf. Acesso em: Acesso em: 12. set. 2014.

BORGES, L. O; TAMAYO, A. A estrutura cognitiva do significado do trabalho. Revista Psicologia: organizações e trabalho, v. 1, n. 2, p. 11-44, Jul./Dez. 2001.

BORGES, L.O; ALVES FILHO, A.A \& TAMAYO, A. Motivação e significado do trabalho. In: SIQUEIRA, M.M.M. (Org.). Medidas do comportamento organizacional: ferramentas de diagnóstico e gestão. Porto Alegre: Artmed, 2008, p. 215-247.

BRASIL. Lei ${ }^{\circ}$ 8.112, de 11 de dezembro de 1990. Dispõe sobre o regime jurídico dos servidores públicos civis da União, das autarquias e das fundações públicas federais. Diário Oficial da União, Brasília, DF, 19 abr., 1991.

BRASIL. Lei $n^{\circ} 11.091$, de 12 de janeiro de 2005. Dispõe sobre a estruturação do Plano de Carreira dos Cargos Técnico-Administrativos em Educação, no âmbito das Instituições Federais de Ensino vinculadas ao Ministério da Educação, e dá outras providências. Diário Oficial da União, Brasília, DF, 13 jan, 2005.

BRASIL. Ministério da Educação. Portaria nº 540/2012. Instituto Federal de Educação, Ciência e Tecnologia de Goiás, Goiânia, 2012 c. Disponível em: < http://www.ifg.edu.br/gdrh/downloads/portaria/portaria\%20540.pdf>. Acesso em: 15 set. 2014.

BRASIL. Ministério da Educação. Regulamento da flexibilização da jornada de trabalho dos servidores técnico-administrativos em educação do Instituto Federal Goiano. Instituto Federal Goiano, Goiânia, 2013b. Disponível em: < http://www.ifgoiano.edu.br/home/wp-content/uploads/2011/04/ANEXO-DAPORTARIA-N\%C2\%BAxxx-PROPOSTA-DGP-final-2-elias.pdf $>$. Acesso em: 12 nov. 2014.

BRASIL. Ministério da Educação. Universidade Federal de Goiás. Estatuto da UFG. Universidade Federal de Goiás, 2014a.

BRASIL. Ministério da Educação. Instituto Federal de Educação, Ciência e Tecnologia de Goiás. Instituição. Instituto Federal de Educação, Ciência e Tecnologia de Goiás, 2014b.

BRASIL. Ministério da Educação. Instituto Federal Goiano. Cursos. Instituto Federal Goiano, 2014d.

Revista Eletrônica Gestão e Serviços v.9, n. 2, pp. 2473-2495, julho/dezembro 2018.

ISSN Online: 2177-7284 e-mail: regs@metodista.br 
BRITO, v. J. M. B., RÉGIS, H.P. ; MORAES, W.F.A. Gestão da Estratégia e Motivação: um estudo de caso na Companhia Hidro Elétrica do São Francisco CHESF. In: Encontro de Estudos Organizacionais da ANPAD, 6., 2010. Florianópolis. Anais... Rio de Janeiro: ANPAD, 2001.

ÇALIŞKAN, E. The Impact of Strategic Human Resource Management on Organizational Performance. Journal of Naval Science and Engineering, v. 6, n. 2, p. 100-116. Disponível em:

https://pdfs.semanticscholar.org/ef18/5f538ef545d30478821893672e81201ddf78.pdf . acesso. 25. Out. 14.

CAMPELLO. J. R. B. C. Satisfação no trabalho e motivação: um estudo sobre os profissionais de tecnologia da informação. 2010. 174f. Dissertação (Mestrado em Administração de Empresas) - PUC-RIO, Rio de Janeiro: UNIVERSIDADE FEDERAL FLUMINENSE, 2010.

CARVALHO, V.D.; SOUZA, W.J. DE. Pobres no ter, ricos no ser: trabalho voluntário e motivação na Pastoral da Criança. Revista de Administração Contemporânea (RAC), v. 11, n.2, p. 113-34, Abr./ Jun. Curitiba: RAC, 2007.

EVANGELISTA, W. L.; COSTA, F. R. Motivação de funcionários do serviço público federal de Bambuí-MG. In: JORNADA CIENTÍFICA, 1, e FIPA DO CEFET BAMBUÍ, 6, 2008, Bambuí. Anais...Bambuí, 2008.

FADUL, E.M. C. Redefinição de espaços e papéis na gestão de serviços públicos: fronteiras e funções da regulação social. Revista de Administração Contemporânea (RAC), v.1, n.1, p. 55-70, Curitiba: Jan./Abr. 1997.

FERREIRA, A.J.C.A. Motivação dos trabalhadores na sociedade do conhecimento. Data. Número de folhas. Dissertação (Mestrado em Gestão de Empresas) - Faculdade de Economia e Gestão da Universidade Lusófona de Humanidades e Tecnologias, Lisboa, 2010.

FREIRE, J.R.S. Comportamento organizacional e satisfação no trabalho: uma análise da gestão de recursos humanos. Administração. Diálogo, n.1, p.39-57., 1999.

GALHANAS, C. R.G. A motivação dos recursos humanos nos novos modelos de gestão da administração pública. 2009. 102 f. Dissertação (Mestrado em Ciências Empresariais) - Instituto Superior de Economia e Gestão, Universidade Técnica de Lisboa, Lisboa. 2009.

GONDIM, S. M. G. Trabalho docente e valores: em questão as novas tecnologias de informação e comunicação. Estudos de psicologia. PUC-Campinas, v.18, n.1, p. 46-57. 2001.

GONDIM,S.M. G.; SILVA, N. Motivação no trabalho. In: ZANELLI, J.C.; BORGESANDRADE, J.E.; BASTOS, A.V.B. (Org.). Psicologia, organizações e trabalho no Brasil, p. 145-176. Porto Alegre: Artmed, 2014,

GUEST, D.E. Human resource management and industrial relations. Journal of Management Studies, v.24, n.5, p. 503-521. 2007.

JOB, F.P.P. Os sentidos do trabalho e a importância da resiliência nas organizações. 2003. 242 f. Tese (Doutorado em Administração de Empresas) - Escola de Administração de Empresas de São Paulo (EAESP). São Paulo: Fundação Getúlio Vargas (FGV), 2003. 
LATHAM, G. P.;PINDER, C. C. Work motivation theory and research at the dawn of the Twenty-First Century. Annual Reviews Psychology, v.56, p. 485-516. 2005.

MALVEZZI.S. Prefácio. In: ZANELLI, J.C.; BORGES-ANDRADE, J.E.; BASTOS, A.V.B. (Org.). Psicologia, organizações e trabalho no Brasil, p. 145-176. Porto Alegre: Artmed, 2014.

MARIANI, C.A.; SILVA, L. H. M. O Comportamento Organizacional é visto como um diferencial competitivo para a organização? Revista de Administração da UNIMEP,v. 2, n. 3, p. 59-82, Set. / Dez. 2004.

MENDONÇA, H.; TAMAYO, A. Valores pessoais e retaliação organizacional: estudo em uma organização pública organização pública. RAC-Eletrônica, v.2, n.2, p. 189-200. Curitiba: RAC. 2008.

MORIN, E. M. Sentidos do trabalho. Revista de Administração de Empresas (RAE), v.41, n. 3, p. 8-19, Jul./Set. São Paulo: ERA.2001.

PEREIRA, L.C.B. Os primeiros passos da reforma gerencial do Estado de 1995. Revista Brasileira de Direito Público - RBDP, ano 6, n.23, p. 145-186, Out./Dez. Belo Horizonte: RBDP. 2008.

PEREIRA, V. S. A motivação do trabalhador bancário. 2008. 83 f. Monografia (Graduação) - Faculdades de Ciências da Educação e Saúde. Brasília: UNICEUB. 2008.

PRAZERES, A.F. Significado e motivação no trabalho: estudo de caso em uma empresa de Usinagem Mecânica e Caldeiraria da Região dos Inconfidentes de MG. 2013. 112 f. Dissertação (Mestrado em Administração) - Faculdade Novos Horizontes. Belo Horizonte: Unihorizontes, 2013.

PRESTES, E.M.T.; JEZINE, E; SCOCUGLIA, A. C. Democratização do Ensino Superior Brasileiro: O caso da Universidade Federal da Paraíba. Revista Lusófona de Educação, [S.1.], v. 21, n. 21, p. 199-218, oct. 2012. ISSN 1646-401X. Disponível em: <http://revistas.ulusofona.pt/index.php/rleducacao/article/view/3088>. Acesso em: 29 dec. 2014

QUADROS, D.; TREVISAN, R.M. Comportamento organizacional. Gestão do capital humano, v.5. Coleção Gestão Empresarial: Curitiba, 2002.

QUEIROGA, F. Seleção de pessoas e desempenho no trabalho: um estudo sobre a validade preditiva dos testes de conhecimentos. 2009. $223 \mathrm{f}$. Tese (Doutorado em Psicologia Social, do Trabalho e das Organizações). Brasília: Instituto de Psicologia, Universidade de Brasília (UNB), 2009.

RÉGIS, H.P.; CALADO, S.M. R. A Teoria da Expectância em um modelo de escolha do tipo "Within-Subject": um teste empírico da sua validade para a cultura brasileira. In: Encontro Nacional dos Programas de Pós-Graduação de Administração, 25, 2001, Campinas. Anais... p. 310-311. Rio de Janeiro: ANPAD, 2001.

RIBEIRO, A.L. Gestão de pessoas. São Paulo: Saraiva, 2005.

ROBBIN, S.P. Comportamento organizacional. 11. ed. São Paulo: Pearson Prentice Hall, 2005.

RODRIGUES, W. A.; REIS NETO, M. T.; GONCALVES FILHO, C. As influências na motivação para o trabalho em ambientes com metas e recompensas: um estudo no setor público. Revista de. Administração Pública [online], v. 48, n.1, p. 253-273, 
2014. Disponível em: http://www.scielo.br/scielo.php?pid=S0034-

$76122014000100011 \&$ script=sci_abstract\&tlng=pt. Acesso em: $25.0 u .2015$

SCHERMERHORN, R. J., Hunt, G. J., \& Osborn, N. R. (1999). Fundamentos do Comportamento Organizacional. (2ed.). Porto Alegre: Bookman, 2008.

SOARES, C.; SOARES, R. M. Valores associados ao trabalho: um estudo com a população residente na Covilhã. Análise Psicológica, n.32, p. 91-103. Lisboa: 2014. Disponível em: http://www.scielo.mec.pt/pdf/aps/v32n1/v32n1a06.pdf. Acesso em: 10.ago. 2015

TAMAYO, A.; PASCHOAL, T. A relação da motivação para o trabalho com as metas do trabalhador. Revista de Administração Contemporânea (RAC), v. 7, n. 4, p. 3354, Out./Dez. Curitiba: 2003. Disponível em:

http://www.scielo.br/pdf/rac/v7n4/v7n4a03.pdf. Acesso em: 21.out.2014

TOLFO, S.R; PICCINI, V. Sentidos e significados do trabalho: explorando conceitos, variáveis e estudos empíricos brasileiros. Psicologia \& Sociedade, V.19, Edição Especial n.1, p. 38-4. 2007. Disponível em:

http://www.scielo.br/scielo.php?pid=S0102-

$71822007000400007 \&$ script=sci_abstract\&tlng=pt. Acesso em: 20. set.

VOLGEMANN, E. Flexibilização da carga horária como forma de motivação organizacional. Porto Alegre: Escola de Administração da Universidade Federal do Rio Grande do Sul, 2012.

VROOM, V. H. Work and motivation. São Francisco: Jossey-Bass Publishers, 1995. 